\title{
OPTIMIZATION OF ESTHETIC REHABILITATION IN TOOTH WITH ENDODONTIC IMPAIRMENT
}

\author{
Paulo Augusto Pires Milani ${ }^{1}$, Thalita Matos $^{2}$, Leonardo Pelissari ${ }^{1}$, Fabiano de Oliveira \\ Araujo $^{1}$, Willian Lacerda ${ }^{3}$, Matheus Coêlho Bandéca ${ }^{1}$, and Yasmine Pupo ${ }^{3}$ \\ ${ }^{1}$ Universidade Tuiuti do Parana \\ ${ }^{2}$ Tuiuti University of Parana \\ ${ }^{3}$ Universidade Federal do Parana
}

January 27, 2022

\begin{abstract}
There is need to optimize dental procedures for better productivity and patient acceptance, without, however, reducing the quality of the results obtained. The objective of this work is to present a clinical case that illustrates endodontic retreatment followed by installation of a fiber glass post and coronary preparation.
\end{abstract}

\section{INTRODUCTION}

Esthetics outcomes are a growing concern of human beings, and this leads to a constant search for beauty that expresses harmony and naturalness. In this sense, restorative procedures have contributed positively to the resolution of esthetic dental challenges (1). In addition, every day there is a greater need to streamline the duration of dental procedures in order to keep up with the pace of modern life, without, however, reducing the quality of the results obtained (2). Restoring endodontically treated teeth is a permanent challenge in Dentistry, as biomechanical, esthetic and technical aspects may result in failure and the possibility of tooth loss (3). The clinical situation becomes even more challenging when failure in endodontic treatment leads to the need for retreatment of the root canals (4). In this context, simultaneous root and coronary restoration in a single session, when possible, presents itself as an advantageous restorative possibility, since the endodontist is familiar with the root canal system for its preparation and can also maintain the aseptic chain of the procedure in the same session (5). The esthetic and functional rehabilitation of endodontically treated teeth with loss of a large amount of coronary structure requires, in most cases, the use of intraradicular retainers as an additional way to stabilize and retain the restorative material (6). The combination of fiberglass posts and composite resin filler cores have gained popularity in recent years due to their mechanical and esthetic properties. Because they have a modulus of elasticity similar to dentin, it drastically reduces the risk of root fracture, when compared to metallic and ceramic retainers, due to better stress distribution (7). The coronary restorative procedure to restore the biomechanical and esthetic balance, should also employ materials that have properties similar to those of the tooth structure to be replaced (8). Metal-free reinforced ceramic systems have emerged as an alternative to conventional porcelains for providing excellent esthetics, greater fracture resistance, and less crack propagation than conventional feldspathic ceramic systems (9). The combination of these restorative materials with the evolution of adhesive cementation techniques has made this treatment approach an alternative highly viable to classical and more invasive forms of restorative treatment (10). The objective of this work is to present a clinical case that illustrates the endodontic 
retreatment followed by installation of a fiberglass post, coronary preparation and preparation of a provisional in a single session and subsequent rehabilitation with a metal-free ceramic crown.

\section{CASE REPORT}

A 54-year-old female patient presented to the dental office reporting dissatisfaction with the esthetics of her left upper incisor (tooth 12). On clinical examination, there was a loss of coronary material at the middle third of tooth 12 and the presence of temporary restorative material (Figure 1 - A and B). The radiographic examination revealed the presence of an apical lesion associated with incomplete filling of the root canal, characterizing chronic apical periodontitis (Figure 1 - C). Considering the diagnosis, the remaining tooth and the need for both endodontic and restorative treatment, the endodontic retreatment was planned, followed by the installation of a fiberglass post associated with a composite resin filling core, for subsequent prosthetic rehabilitation with a full crown. Before starting the treatment, a fiberglass post (Whitepost DC - FGM, Joinville - SC, Brazil) was selected to be installed in the root canal. The procedure started with isolation of the operative field and opening of the cavity with a 1014 drill and irrigation with saline solution. The primary guta percha removal was performed with a Gates Glidden drill (Maillefer/Dentsply, Ballaigus, Switzerland) and the secondary removal with a 20/06 file and a 30/10 file (ProDesign SEasy, Belo Horizonte, MG, Brazil) preparing the canal body. Then, an ultrasonic tip R1 - Clearnsonic (Helse Ultrasonic - Santa Rosa do Viterbo, SP, Brazil) was used to remove the remaining gutta-percha from the walls of the root canal with the aid of an optical microscope for magnification. Guta percha removal in the apical third was performed with C Pilot files (VDW, Munich, Germany) 10 and 15, followed by foraminal enlargement with a 40/05 file (ProDesign Logic - Easy). During preparation, abundant irrigation with saline and chlorhexidine gel was performed. The root canal filling was preceded by EDTA application (Maquira Indústria de Produtos Odontológico Ltda., Maringá, PR, Brazil) with abundant agitation for 3 minutes followed by drying with extra-fine tips (Capillary tips - Ultradent, South Jordan, ST, USA ) and calibrated absorbent paper on the final anatomical file. The filling was then performed using a single calibrated gutta-percha cone at the base of the final anatomical file and endodontic cement (Endomethasone N Septodont, Saint Maur, France) leaving adequate space for the fiberglass post. The chosen post was tested in the root canal in order to check its adaptation to the prepared canal (Figure $2-\mathrm{B}$ ). To obtain the greatest possible adaptation, the post was reanatomized with composite resin (Charisma Classic - Kulzer, Wehrheim, Germany) (Figure 2 - C). For this, the canal was isolated with a chlorhexidine gel. The post was conditioned with $37 \%$ phosphoric acid (Condac 37 - FGM, Joiville, SC, Brazil) for 15 seconds, washed for 30 seconds and dried with an air jet. A thin layer of silane (Prosil - FGM) was applied to the post using a disposable applicator (Cavibrush FGM), and dried with a light jet of air after one minute as indicated by the manufacturer. Composite resin was applied around the post and the post was inserted into the root canal. This set was light cured for 10 seconds and then removed from the conduit to finish its light curing out of position for another 40 seconds each face (mesial, distal, buccal and palatal). Afterwards, dentin conditioning was performed for the post cementation step. The self-etching adhesive system (Clearfil SE Bond - Kurakay, Osaka, Japan) was applied following the manufacturer's instructions. After root cleaning with chlorhexidine gel, the primer was applied using extra-fine disposable applicators (KG Brush - KG Sorensen, Barueri, SP, Brazil), in all areas of root dentin and coronary enamel for 20 seconds together with light air jet for 5 seconds, the excess was removed with extra-fine tips (Capillary tips - Ultradent). Then the bond component was applied in the same way. The dual resin cement (Allcem Core - FGM) for the fiberglass posts was inserted inside the conduit using a specific mixing tip. The pin was then positioned in the conduit and light cured for 40 seconds. The coronal portion was filled with composite resin (Charisma Classic - Kulzer), and it was also light-cured for 40 seconds (Figure $2-\mathrm{C}$ ). Afterwards, the absolute isolation was removed and the supragingival coronary preparation was carried out for a total ceramic crown using a \#4138 diamond tip (KG Sorensen), at an average depth of $1.0 \mathrm{~mm}$ (Figure $3-\mathrm{A}$ ). At the end of the first session, a provisional restoration was performed using a veneer from a prefabricated tooth (Biotone - Dentisply, Petrópolis - RJ, Brazil) relined with self-curing acrylic resin (JET - Classico, São Paulo, SP, Brazil). The provisional restoration was finished and polished using a cutter 
and rubber kit (Professor Marcelo Hayashida Kit - Dhpro, Paranaguá, PR, Paraná) and it was cemented with temporary cement (Temp-bond NE - Kerr, Scafati, Salerno, Italy ) (Figure 3 - B). Through periapical radiography it was possible to observe that the endodontic treatment was satisfactory with adequate apical sealing (Figure $3-\mathrm{C}$ ). The second session proceeded with the refinement of the preparation and impressions. It began with the removal of the temporary restoration and gingival retraction to complete the preparation at the subgingival level (Figure 4 - A and B). The thinnest cord selected \#000 (Ultrapack - Ultradent) impregnated in hemostatic solution (Viscostat - Ultradent) was inserted into the gingival sulcus followed by the second retractor cord \#00 (Ultrapack - Ultradent) and subgingival extension of the preparation was performed using diamond tip \#4138 (KG Sorensen) (Figure 4-C). The finishing of the corners and edges was carried out with medium and fine grain sandpaper discs (Soflex pop-on - 3M Espe, St. Paul, MN, USA) and diamond tip \#4138 F (KG Sorensen) (Figure 4 - D). After completion of the preparation, the impression was taken using the two-step technique. The molding material used was addition silicone (President - Coltene, Altstatten, Switzerland) (Figure 5). After selecting the tray, the first molding was carried out with the heavy material, performing tilting movements in order to create space for the light material. After its setting and removal from the tray, the most superficial retractor wire was removed and the tray was loaded with the light silicone and placed in position in the mouth. Finally, the tray was removed from the mouth and the impression was washed under running water and sent to the laboratory for the fabrication of vitreous ceramic restorations based on lithium disilicate (IPS e.max, Ivoclar Vivadent, Schaan, Liechtenstein). Color selection was made using specific scale. The provisional restoration was relined with self-curing acrylic resin (JET - Classic); the finishing and polishing was done using a milling and rubber kit (Professor Marcelo Hayashida Kit - Dhpro) and it was cemented with temporary cement (Temp-bond NE - Kerr). In the third session, with the ceramic piece in hand (Figure $6 \mathrm{~A}$ and $\mathrm{B}$ ), the provisional was removed, the preparation was cleaned using a Robson brush (Figure $6 \mathrm{C}$ ), and the crown was tested in the mouth to verify esthetics and adaptation. For cementation, absolute isolation of the operative field was performed. The enamel area of the preparation was etched with $37 \%$ phosphoric acid (Condac 37 - FGM) for 30 seconds, washed for 30 seconds and dried with an air jet. Then, the self-etching adhesive system (Clearfil SE Bond - Kurakay) was applied following the manufacturer's instructions followed by light curing for 10 seconds on each face. The internal conditioning of the piece was performed with $10 \%$ hydrofluoric acid (Biodynamics - Ibipora, PR, Brazil) for 20 seconds, followed by washing and drying (Figure 7 A). It was then conditioned with $37 \%$ phosphoric acid (Condac 37 - FGM) for 15 seconds, followed by washing and drying for application of Silane (Prosil - FGM) (Figure 7 - B and C). Finally, the dual resin cement (Allcem Core - FGM) was applied inside the ceramic crown and finally, the piece was placed in the preparation (Figure $8 \mathrm{~A}$ ). Excess cement was removed from the margins using a spatula and brush. Then, light curing was carried out for 40 seconds on each face (vestibular, incisal and palate). Subsequently, the occlusal adjustment was performed using Accufilm carbon paper (Parkell - Farmingdale, NY, USA). The esthetic and functional result obtained was satisfactory and satisfied the patient's complaint (Figure 8 - B and C).

\section{DISCUSSION}

The prosthetic rehabilitation of an endodontically treated tooth is a factor that can significantly influence the success of restorative treatment $(3,5)$. This paper illustrates a clinical case in which, due to a precise approach with endodontic retreatment followed by installation of a fiberglass post, prosthetic preparation and making a provisional in a single session, the prosthetic rehabilitation process was optimized. This single-session endodontic and restorative approach illustrated in this work is described in the literature as the BCR (simultaneous coronal shielding) concept, which is a technique for simultaneous preparation and restoration of both the root and coronary canal system. It is a planned biomechanical preparation aiming at the immediate installation of an intraradicular fiberglass retainer, concluding with the definitive restoration of the endodontically treated tooth, with resin and/or ceramic materials, considering clinical, mechanical and biological aspects of the tooth (5). It is important to point out that, in cases like the present one, there are some advantages for the endodontist to perform the intraradicular restorative procedures in the 
same session. From a biological point of view, the need for a provisional restoration in an approach in more than one session is a critical point after endodontic treatment, because if there is no good adaptation of the restoration, there is a great risk of bacterial infiltration (11). Carry out the preparation intraradicular and installation of the fiberglass post immediately after the endodontic treatment maintains the aseptic chain, avoiding contamination of the root canals by saliva and also eliminates moisture and fluids from the oral environment that can impair adhesion $(5,12)$. Furthermore the endodontist is more familiar with the morphology of the root canal system and its working length, and there is less risk of fracturing the coronal tooth tissue, thus losing the reference point from which the working length was determined. This leads to the proper amount of gutta-percha removal and lower risk of perforation (13). The purpose of the intraradicular retainers, such as the fiberglass posts used in the present clinical case, is to provide retention and stability for the restorative materials (6). Regarding fracture resistance, the literature shows that a higher rate of root fracture occurs in teeth with prefabricated stainless steel posts and not those with non-metallic posts (15). This is due to the modulus of elasticity of fiberglass posts, which are more similar to root dentin, thus the tension of the forces incident on the post. and the root can be distributed more evenly (16). In cases of failure in which a filling core with a fiberglass post is used, the post usually fractures or loosens, which is still subject to repair or new restoration (17). On the other hand, the literature recommends that if the height of the coronary remnant is less than $2 \mathrm{~mm}$. Fiberglass posts compared to cast metal cores have great esthetic advantages. In addition, without the laboratory phase, the result is a reduction in clinical steps, as well as costs, and also a lower loss of healthy tooth structure for the manufacture of a filling core in composite resin $(16,17)$. These advantages are especially applied in cases such as the present one where the use of fiberglass post enabled the completion of the prosthetic preparation after endodontic retreatment in the same session, optimizing the restorative process. The morphological differences along the root canal can lead to a mismatch between the diameter of the post and the space occupied by it, leading to an increase in the thickness of the resin cement. Therefore, the reanatomization of the post with composite resin has been proposed, reducing the thickness of the resin cement layer, improving frictional retention and creating a better adaptation to the root canal (18). It is noteworthy that for the cementation of these posts, it is necessary to whether a chemically activated or dual cement, as there is difficulty in the transmission of light to the apical third (19). In order to meet these recommendations, in the present clinical case the fiberglass post used was reanatomized with composite resin and for its cementation it was used. if dual resin cement. In the coronal portion of the filling core, definitive restoration is another important component in the final reconstruction, both morphologically and esthetically (5). Metal-free ceramic crowns are an excellent restorative alternative, provided that the clinical protocol of mechanical preparation and adhesive cementation is correctly followed (20). Some authors have reported success in restoring the esthetics of elements in the esthetic zone when using ceramic systems reinforced with lithium disilicate due to their excellent esthetic properties and high strength (8). Furthermore, ceramic restorations offer long-term stability and durability and may have higher failure rates when associated with cases of patients with parafunctional habits such as bruxism (21). The indication of a metal-free ceramic restoration for the patient in this clinical case to the expectations of esthetics in the smile because it is a lateral incisor.

\section{CONCLUSION}

The treatment approach illustrated in this clinical case with endodontic retreatment followed by installation of a fiberglass post, coronary preparation and preparation of the provisional in a single session, optimized the subsequent rehabilitation with a ceramic crown, reducing the clinical time and having good acceptance by the patient. This procedure, when performed by a qualified professional, presents satisfactory esthetic and functional results.

Author Contributions:

Paulo Augusto Pires Milani: Case Report Methodology; Supervision.

Leonardo Pelissari: Execution of case report planning and writing - original draft. 
Fabiano de Oliveira Araujo: Photo sequence and Writing - review \& editing.

Willian Lacerda: Formal analysis; Methodology; Writing - review \& editing.

Thalita de Paris Matos: Formal analysis; Methodology; Writing - review \& editing.

Matheus Coelho Bandeca: Methodology; Writing - review \& editing.

Yasmine Mendes Pupo: Conceptualization; Methodology; Project administration; Supervision; Validation; Writing - review \& editing.

\section{REFERENCES}

1. Carolina Hintz R, Saab RC, Garcia E, Hilgenberg SP, Da Cunha LF, Deliberador TM, et al. Artigo de Relato de Caso. Vol. 5, RSBO Revista Sul-Brasileira de Odontologia. 2018.

2. Chagas L, Lopes M, Filho E, Filho T. Tratamento endodontico em sessao unica. RGO. 2000;48(3):13740.

3. Reis B, Soares P, Castro CG, Santos Filho PCF, Soares P, Soares C. Uso de Coroa em Ceramica Pura Associada a Pino de Fibra de Vidro na Reabilitacao Estetica do Sorriso: Relato de Caso. Rev Odontol Bras Cent. 2010;19(50):264-9.

4. Garcia Junior J, Neto U, Carneiro E, Westphalen V, Fariniuk L, Fidel R, et al. Assessment of the Effectiveness of Different Rotary Instruments in Endodontic Retreatment. Rev SulBrasileira Odontol. 2008;5(2):41-9.

5. Valdivia JE, Machado ME de L. Simultaneous crown-root shielding in endodontics: From root preparation to coronary restoration. Dent Press Endod. 2017;7(1):32-42.

6. Pegoraro LF, Valle AL do, Araujo C dos RP de, Bonfante G, Conti PCR, Bonachela WC. Protese Fixa. Sao Paulo: Artes Medicas; 1998.

7. Baltieri P. Fundamentos essenciais na remocao de pinos pre-fabricados nao metalicos: onde a magnificacao faz a diferenca? In: Worschech, C; Murgel C, editor. Micro-odontologia: visao e precisao em tempo real. Maringa: Dental Press; 2008. p. 350-8.

8. Clavijo V, Souza N, Estet MA-R dental press, 2007 U. IPS eMax: harmonizacao do sorriso. Rev Dent Press Estet. 2007;33-49.

9. Hondrum SO. A review of the strength properties of dental ceramics. J Prosthet Dent. 1992;67(6):85965.

10. Edelhoff D, Prandtner O, Pour RS, Liebermann A, Stimmelmayr M, Guth JF. Anterior restorations: The performance of ceramic veneers. Quintessence Int (Berl). 2018;49(2):89-101.

11. Heling I, Gorfil C, Slutzky H, Kopolovic K, Zalkind M, Slutzky-Goldberg I. Endodontic failure caused by inadequate restorative procedures: review and treatment recommendations. J Prosthet Dent. 2002 Jun;87(6):674-8.

12. Goldfein J, Speirs C, Finkelman M, Amato R. Rubber dam use during post placement influences the success of root canal-treated teeth. J Endod. 2013 Dec;39(12):1481-4.

13. Ricketts DNJ, Tait CME, Higgins AJ. Tooth preparation for post-retained restorations. Br Dent J. 2005 Apr 23;198(8):463-71.

14. Endo MS, Santos ACL dos, Pavan AJ, Queiroz AF, Pavan NNO. Endodontia em sessao unica ou multipla: revisao da literatura. Rev da Fac Odontol - UPF. 2016;20(3):408-13.

15. Newman MP, Yaman P, Dennison J, Rafter M, Billy E. Fracture resistance of endodontically treated teeth restored with composite posts. J Prosthet Dent. 2003 Apr;89(4):360-7.

16. Mazzoccato DT, Hirata R, Pires LAG, Mota E, de Moraes LF, Mazzoccato ST. Propriedades flexurais de pinos diretos metalico e nao - metalicos. R Dent Press Estet. 2006;3(3).

17. Albuquerque R, Alvim H. Pinos pre-fabricados e nucleos de preenchimento. In: Mendes W, Miyashita E, editors. Reabilitacao Oral: Previsibilidade e longevidade. Sao Paulo: Editora Napoleao; 2011. p.393-418. 
18. Rodrigues RV, Sampaio CS, Pacheco RR, Pascon FM, Puppin-Rontani RM, Giannini M. Influence of adhesive cementation systems on the bond strength of relined fiber posts to root dentin. J Prosthet Dent. 2017 Oct 1;118(4):493-9.

19. Albuquerque RC. Pinos intra-radiculares pre-fabricados. In: Cardoso R, Goncalves E, editors. Oclusao atm, protese, protese sobre implantares, protese bucomaxilofacial. Porto Alegre: Artes Medicas; 2012. p.441-62.

20. Durao M de A, Junior WB, Braz R, De Brito DHS, Siveira MAC, Briano D de B. Aprimorando a Estetica com Coroas "Metal Free": Relato de Caso. Odontol Clinico- Cientifica. 2015;14(3).

21. Beier US, Burtscher IKD, Dumfahrt H. Clinical performance of porcelain laminate veneers for up to 20 years. J Prosthet Dent. 2012;107(3):157.

\section{FIGURES}
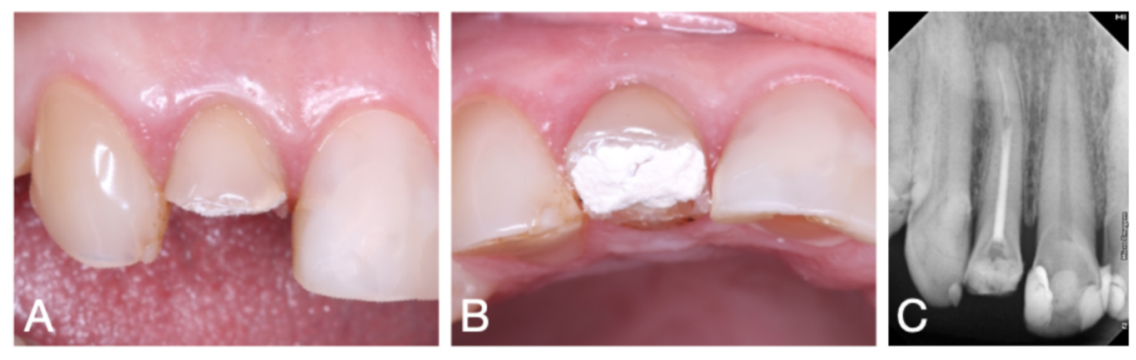

Figura 1. (A and B) Intraoral photos showing the initial appearance of tooth 12; (C) periapical radiograph unsatisfactory endodontic treatment of tooth 12 .
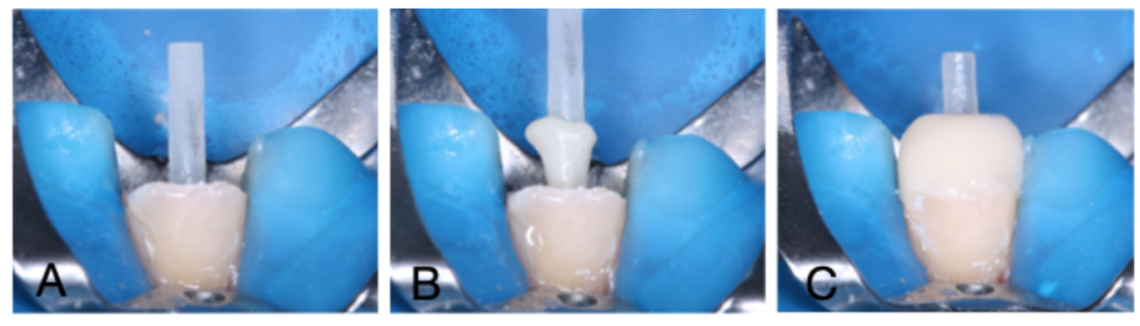

Figura 2. Post test in the root canal; (B) Reanatomization of the post with composite resin; (C) composite resin filling core after post cementation.
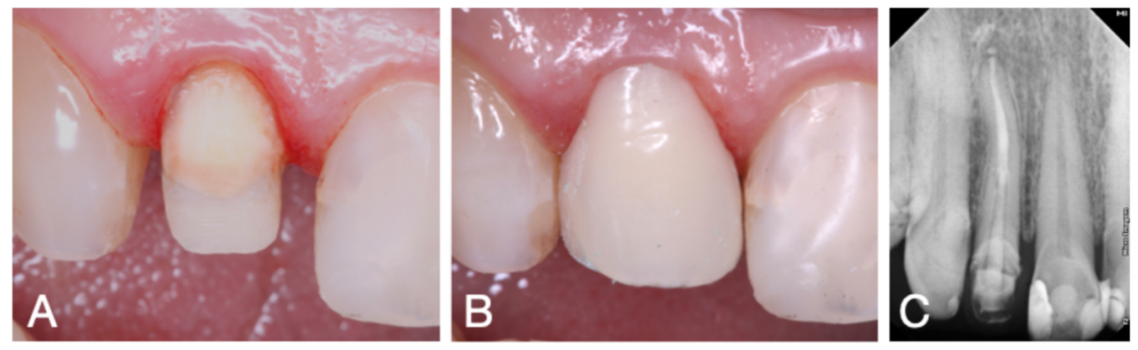

Figura 3. Aspect of the initial supragingival preparation; (B) provisional restoration; (C) radiographic appearance after endodontic retreatment shows adequate apical sealing. 


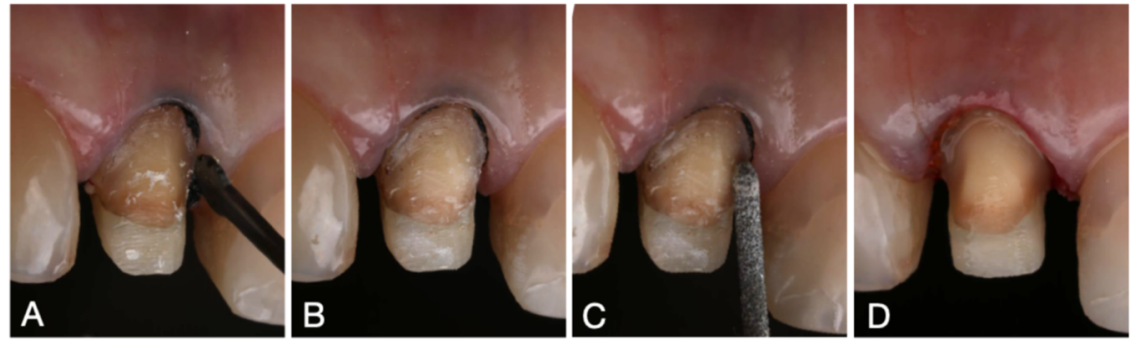

Figura 4. (A and B) Gingival retraction with retractor wire; (C) Subgingival extension of the 4138 diamond tip preparation; (D) final aspect of the preparation.
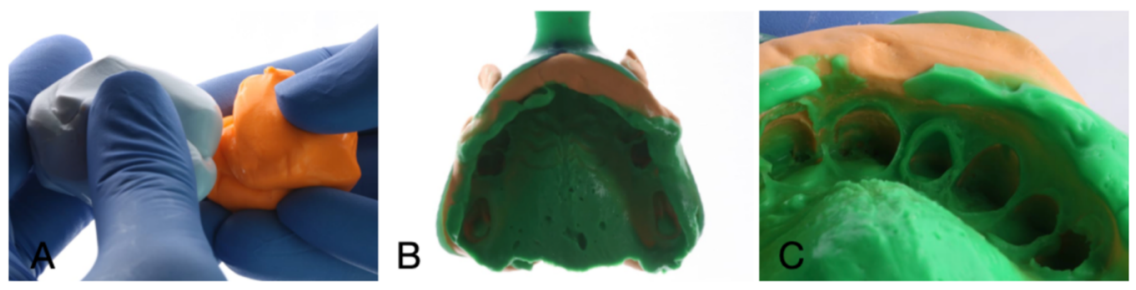

Figura 5. (A) Mix of heavy silicone addition material; (B and C) aspect of the mold.
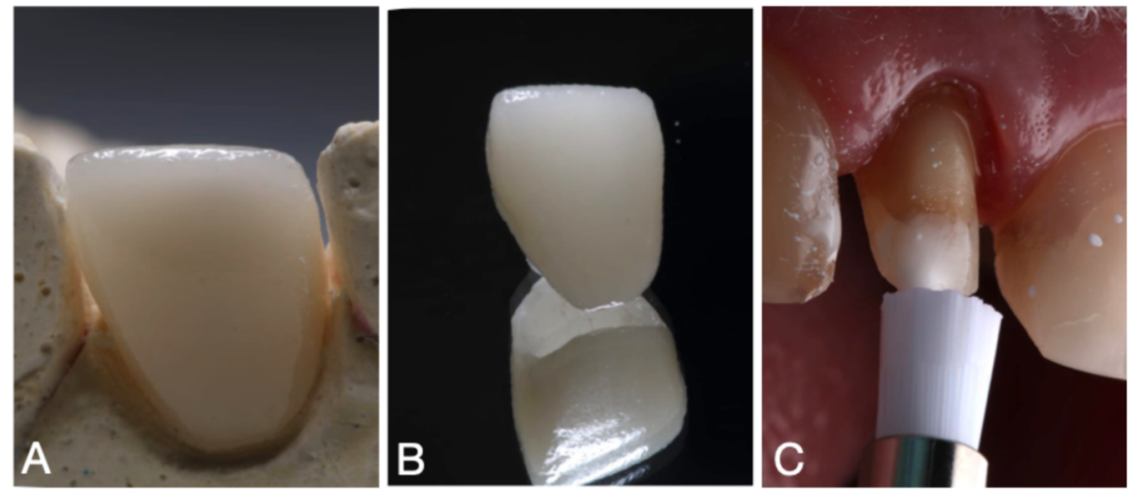

Figura 6. (A and B) Lithium disilicate ceramic crown; (C) cleaning the preparation with a Robson brush.
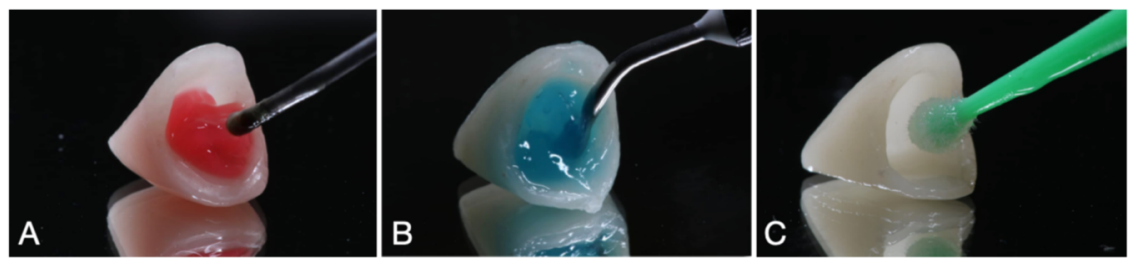

Figura 7. (A) Internal conditioning of the crown with $10 \%$ hydrofluoric acid; (B) internal cleaning with $37 \%$ phosphoric acid; (C) silane application. 


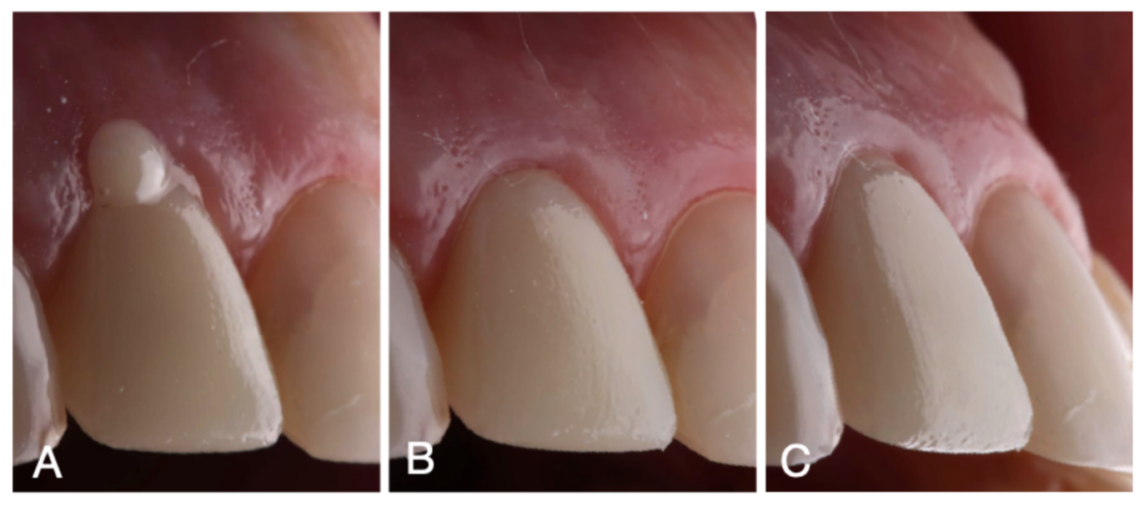

Figura 8. (A) Cementation of lithium disilicate crown with resin cement; (B and C) final appearance after cementation. 